\title{
Correction to: A Study Examining the Orbera365 Intragastric Balloon Safety and Effects on Weight Loss
}

\author{
Mohammad H. Jamal ${ }^{1,2}$. Nour Al-Kanawati ${ }^{2} \cdot$ Rawan ElAbd $^{1} \cdot$ Mohannad Al-Haddad $^{3} \cdot$ Talal AlKhadher $^{4}$. \\ Fatima Hamshari ${ }^{2}$. Shehab Akrouf ${ }^{4}$
}

Published online: 9 December 2021

○) Springer Science+Business Media, LLC, part of Springer Nature 2021

\section{Correction to: Obesity Surgery (2021) 31:5342-5347 \\ https://doi.org/10.1007/s11695-021-05729-8}

Several mistakes in the manuscript text were missed before this article was published; the authors apologize for any inconvenience caused.

Publisher's Note Springer Nature remains neutral with regard to jurisdictional claims in published maps and institutional affiliations.

The original article can be found online at https://doi.org/10.1007/ s11695-021-05729-8.

Mohammad H. Jamal

mohammad.jamal@mail.mcgill.ca

1 Department of Surgery, Faculty of Medicine, Health Sciences Center, Kuwait University, Kuwait City, Kuwait

2 Obesity and Metabolic Unit, The Clinic, Kuwait City, Kuwait

3 Department of Surgery, Jaber Hospital, Kuwait City, Kuwait

4 Department of Surgery, Amiri Hospital, Kuwait City, Kuwait 